\title{
Decadal-centennial-scale change in Asian-Pacific summer thermal contrast and solar activity
}

\author{
ZHAO Ping $^{1 *}$, ZHOU XiuJi $^{2} \&$ LIU Ge ${ }^{2}$ \\ ${ }^{1}$ National Meteorological Information Centre, Beijing 100081, China; \\ ${ }^{2}$ Chinese Academy of Meteorological Sciences, Beijing 100081, China
}

Received March 2, 2011; accepted May 16, 2011

To study the temporally varying features of summer thermal contrast between the Asian continent and the adjacent ocean on decadal-centennial time scales and the links between thermal contrast and solar irradiance, we used a time series of the reconstructed Asian-Pacific oscillation index and solar irradiance over the past millennium. The results showed that thermal contrast in the Asian monsoon region has quasi-90-year, 10-13-year, and 3-7-year periods. On the centennial time scale, thermal contrast showed three abrupt changes, occurring in 1305-1315, 1420-1430, and 1625-1635. There is a significant positive correlation between thermal contrast and solar irradiance, which is particularly strong at 250-year, 120-160-year, 60-70-year, and quasi15 -year periods. The three abrupt changes in thermal contrast corresponded to a significantly weakening or strengthening of solar irradiance, lagging 12-22 years behind the solar irradiance, which possibly reflects an effect of solar irradiance on the abrupt change in Asian monsoon climate on the centennial time scale. On the decadal time scale, the abrupt change in the thermal contrast was not closely associated with solar irradiance, which implies that solar activity may not be a major factor affecting the decadal abrupt change in Asian-Pacific thermal contrast. Relative to thermal contrast, the decadal abrupt change in Northern Hemispheric annual mean surface temperature is more closely associated with solar activity, while its centennial abrupt change has a weaker relationship with solar activity.

Asian-Pacific oscillation, decadal-centennial variability, solar activity, abrupt change

Citation: Zhao P, Zhou X J, Liu G. Decadal-centennial-scale change in Asian-Pacific summer thermal contrast and solar activity. Chinese Sci Bull, 2011, 56: 3012-3018, doi: 10.1007/s11434-011-4591-Z

Variations in the East Asian monsoon directly affect precipitation anomalies over China and may cause large-scale droughts or floods, exerting a great influence on local agriculture and economic development. There are many factors affecting the East Asian monsoon, including sea surface temperatures of the tropical Pacific and Indian Oceans, Eurasian and Tibetan snow cover, and Antarctic and Arctic climates [1-7]. Some factors play major roles during a period, while different factors possibly play dominant roles during another period. This complexity leads to a changeable climate over the East Asian monsoon region. Therefore, studying the long-term varying features and associated mechanisms is helpful for the prediction of long-term

\footnotetext{
*Corresponding author (email: zhaop@cma.gov.cn)
}

change in East Asian climate.

Early in the 1970s, Zhu [8] noted the warmer climates during the Sui and Tang dynasties of China and the cooler climate during the Song dynasty. Subsequently, many studies showed that phenomena such as the European Medieval Warm Period (MWP) and the Little Ice Age (LIA) possibly occurred in the Chinese region [9-14] and that during the MWP, a wetter climate occurred in North China and a drier climate to the south of the Yangtze River. During the LIA, there was a drier climate in North China and a wetter climate to the south of the Yangtze River. Zhang et al. [15] further showed that precipitation exhibits a pronounced centennial-scale variation in China. For example, in Beijing, China, there was less precipitation in the 18th and 20th centuries and more precipitation in the 19th century. Wang 
et al. $[16,17]$ analyzed time series of reconstructed temperatures and discovered that air temperatures over eastern China from the second half of the 9th century to the 11th century and in the 13th century were comparable to or slightly lower than those in the 20th century. These results deepen our understanding of the long-term varying regularities of the East Asian monsoon climate.

Recently, the influence of solar activities on climate has received more attention. The results of Wei et al. [18] showed a close relationship between long-term change in the Asian monsoon climate and solar activity. Kodera [19] analyzed the effect of solar activity on the Indian Ocean monsoon. Wu et al. [20] found that solar activity might affect wet-dry climate changes in northwestern China during the past 400 years. Moreover, summer precipitation over eastern China is closely associated with solar activity [21]. These results have shown the relationship between climate changes in the Asian monsoon region and solar activities. However, the relationship between long-term changes in Asian monsoon climate and solar activities are complicated [22] and the mechanisms responsible for the influence of solar activity on regional climate changes are not still clear [19].

Anomalies in Asian monsoons often result from responses of the atmosphere to variations in thermal contrasts between the Asian continent and adjacent oceans [23,24]. The thermal contrast may be used to indicate variability in East Asian monsoon precipitation [24,25]. Thus, it is necessary to investigate the long-term changes in thermal contrast between ocean and land in the Asian monsoon region and their association with the intensity of solar radiation by using different reconstructed climate data over the past millennium. This will deepen our understanding of the long-term varying regularities and causes of changes in the East Asian monsoon climate.

In the present study, the 993-1985 summer mean AsianPacific Oscillation (APO) index reconstructed by Zhou et al. [26], the 1000-1998 solar irradiance index reconstructed by Bard et al. [27], and the 0-2006 annual mean surface air temperature of the Northern Hemisphere reconstructed by Mann [28] were used to study the decadal-centennial-scale abrupt changes in thermal contrasts between the Asian continent and its adjacent oceans through correlation, power spectrum, and running $t$-test analysis methods. Meanwhile, the relationships between the thermal contrast changes and solar irradiance and global climate changes were also analyzed. Variations in degrees of freedom for the running the time series were considered when the statistical confidence level of a correlation coefficient was calculated.

\section{Long-term varying features of thermal con- trast between the Asian continent and the Pacific}

Summer APO index may be defined as a zonal difference of extratropical tropospheric temperature between Asia and the
North Pacific [24]. Variability in the APO is also significantly and positively correlated with a meridional difference of tropospheric temperature between East Asia and tropical western Pacific, with a correlation coefficient of 0.81 during 1958-2001 (at the 99.9\% confidence level) [29]. Thus the APO index may be applied to indicate changes in both zonal and meridional thermal contrasts between East Asia and adjacent oceans and may well indicate the varying features of monsoon precipitation over eastern China on interannual, decadal, centennial, and millennium time scales $[24,26$, 30-32].

Figure 1(a) shows the temporal changes in the reconstructed APO index and Northern Hemispheric annual mean air temperature during 993-1985. It appears that in the MWP, the APO index was generally in a positive phase. The maximum value in 230 years, from 1000 to 1230 , reflects a higher tropospheric temperature over Asia and a lower tropospheric temperature over the extratropical North Pacific and the tropical western Pacific and indicates a stronger summer thermal contrast between Asia and its adjacent oceans. During the LIA, the APO index was persistently in a negative phase in 205 years, from 1420 to 1625 , with the minimum value in 1450-1570, which indicates a weak ocean-land thermal contrast; it was mainly negative from 1740 to 1940 (during a period of about 200 years).

In addition to these centennial-scale changes, thermal contrast also shows interannual and decadal periodic variations. Power spectrum analysis was performed, in which
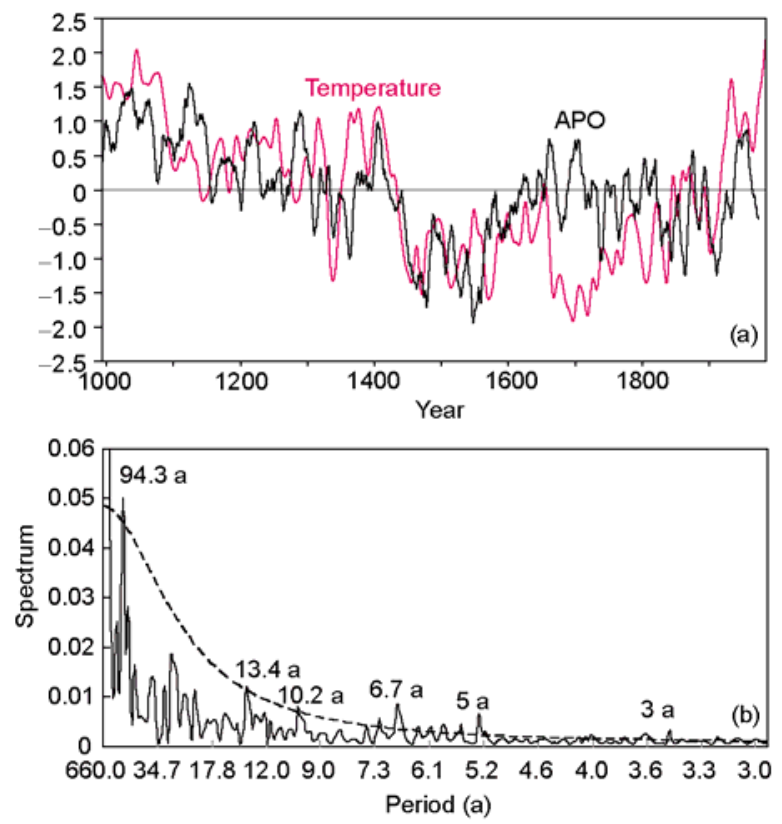

Figure 1 (a) Anomalies in the 9-year running mean values of the summer Asian-Pacific Oscillation (APO) index (black line) and the Northern Hemispheric annual mean air temperature (red line; $\times 0.2^{\circ} \mathrm{C}$ ) reconstructed by Mann [28] during 993-1985, in which the $x$-axis is year and the $y$-axis is values of APO or temperature; and (b) the power spectrum (solid line) of the APO index after removing the linear trend during 993-1985, in which the dashed line is the $90 \%$ confidence level. 
the linear trend of the APO index is removed, because of a significant linear decreasing trend over the past millennium (at the $99.9 \%$ confidence level). Figure 1(b) shows the result of the power spectrum analysis. In the figure, the maximum peaks of the power spectrum of the summer APO index are at 94.3 years, 13.4 years, 10.2 years, and 3-7 years (significant at the $90 \%$ confidence level). The result show that the thermal contrast between Asia and the Pacific has quasi-90-year, 10-13-year, and 3-7-year periodic oscillations, which is similar to the results of the APO index reconstructed from tree-ring width in Sha County, Fujian Province by Chen et al. [33]. Moreover, the interannual and 10 -year periodic variations in thermal contrast are generally consistent with those from stalagmite proxy data in the Wanxiang cave analyzed by Zhang et al. [22]. However, thermal contrast does not show a 170 -year periodic variation that was revealed by stalagmite proxy data in the Wanxiang cave. Moreover, the 90-100-year period in thermal contrast is consistent with that in solar activity (shown in Section 2).

Since an extreme point of the running $t$-test of the temporal mean APO index over a period corresponds to the largest difference of the mean index around this point, the running t-test may be used to detect an abrupt change point of the APO time series. Figure 2(a) shows the running $t$-test value of the 50-year mean APO index during 993-1985. It is seen from the figure that on the decadal time scale, there were six significant positive maximums (at the $99 \%$ confidence level). They appeared in 1110 and 1285 of the MWP and in $1378,1574,1621$, and 1778 of the LIA, indicating
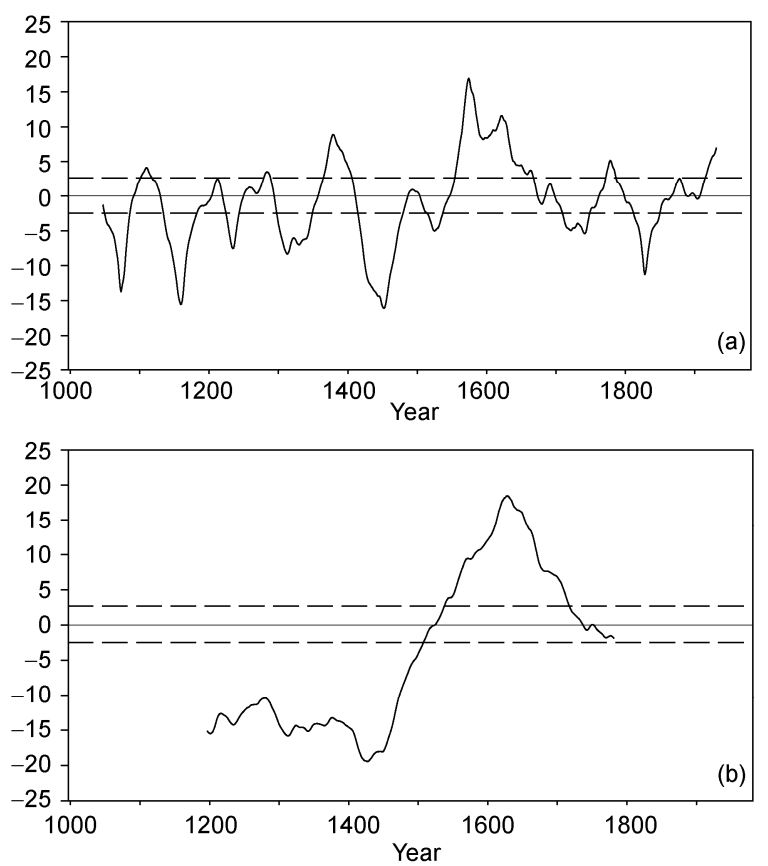

Figure 2 (a) The running $t$-test value (solid line) of the 50-year mean APO index during 993-1985, in which the dashed line is the $99 \%$ confidence level, the $x$-axis is year, and the $y$-axis is the $t$-test value; and (b) same as in (a) but for the 200-year mean APO index. the years with a significantly increasing thermal contrast. The eight significantly negative minimums appeared in $1073,1159,1235$, and 1313 of the MWP and in 1452, 1525, 1740 and 1828 of the LIA, indicating the years with a significantly decreasing thermal contrast. Comparing Figures 1(a) and 2(a), thermal contrast decreased to its weakest and persisted for approximately 100 years after the abrupt change in 1452 . The positive thermal contrast persisted for more than 100 years after the abrupt change in 1621 .

This analysis shows that the thermal contrast between Asia and the Pacific displays a significant quasi-200-year varying feature. The abrupt change in the APO index is examined on the centennial time scale. In Figure 2(b), there were three extreme points, appearing in 1305-1315, 14201430, and 1625-1635, which were significant at the $99 \%$ confidence level. The first abrupt change occurred in the period from the MWP to the LIA, indicating a decreasing ocean-land thermal contrast in the Asian monsoon region and corresponding to the change from a strong Asian monsoon to a weak Asian monsoon. The second abrupt change occurred in the early LIA, showing weakening in the oceanland thermal contrast. The thermal contrast then reached its weakest, which corresponded to the weakest Asian monsoon over the past millennium. The third abrupt change occurred in the middle LIA, representing the change from a weak thermal contrast to a strong one and corresponding to a period when the Asian monsoon strengthened on the centennial time scale. Compared with decadal abrupt changes, there are fewer abrupt change points on the centennial time scales, and the decadal abrupt change points in 1313 and 1621 are generally consistent with those of the centennial abrupt change points.

\section{Relationship between the Asian-Pacific thermal contrast and solar activity}

Over the past 1000 years, solar activity has showed periodic oscillations of 200 years, 90-140 years, 60 years, 22 years, and 11 years, in which the 11-year period is the most dominant period [34,35]. It is evident that the 90-100-year and 10-13-year periods of the Asian-Pacific thermal contrast are generally consistent with those of solar activity, which implies a close link between long-term changes in the Asian-Pacific thermal contrast and solar activity over the past millennium.

Figure 3(a) shows the 9-year running mean value for the 1000-1998 solar irradiance reconstructed by Bard et al. [27]. In the figure, solar irradiance shows a gradually decreasing trend before 1460 and an increasing trend afterwards. This increasing trend is persisting to the present day. Generally speaking, the decrease in solar radiance during 1100-1400 corresponded to weakening of the thermal contrast between Asia and the Pacific, and the lowest solar irradiance also corresponded to the weakest thermal contrast during 1400- 

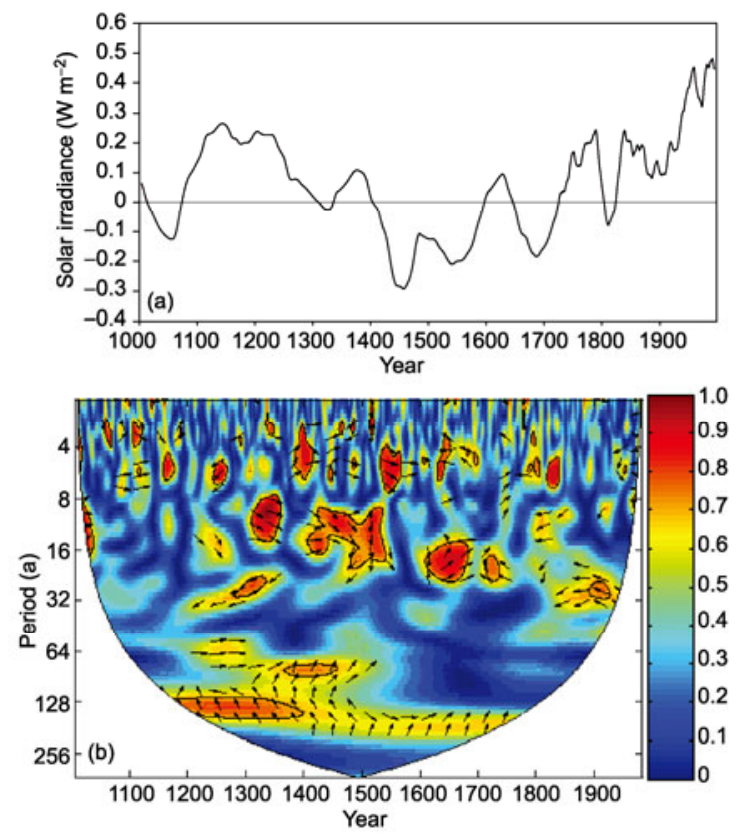

Figure 3 (a) Anomalies in the 9-year running mean value of the 1000-1998 solar irradiance reconstructed by Bard et al. [27], in which the $x$-axis represents the year and the $y$-axis represents values of solar irradiance; and (b) represents the wavelet cross-spectral value between the summer APO index and the solar irradiance index during 1000-1985.

1560. Subsequently, the increase in solar irradiance was generally consistent with that of thermal contrast. The correlation between thermal contrast and solar irradiance is further calculated from data during 1000-1985. The correlation coefficient is 0.31 , and it is significant at the $99 \%$ confidence level. The correlation coefficient between thermal contrast and irradiance is 0.41 , significant at the $99.9 \%$ confidence level, after removing their linear trends. This result further supports the notion that variation in the thermal contrast between Asia and the Pacific is generally consistent with that of solar irradiance. However, it is also noted that there are some differences between thermal contrast and irradiance on the decadal time scale. For example, during the period 1000-1100, solar irradiance is negative, while thermal contrast is positive. Further analysis shows that this difference is possibly because of the reliability of the reconstructed solar irradiance index by Bard et al. [27]. The solar irradiance with an interval of 5 years from the last glacial maximum to 1950 , reconstructed by Reimer et al. [36], shows a higher irradiance value during 1000-1100. Thus, further analysis is needed on the difference between the thermal contrast and the solar activity during this period.

Figure 3(b) shows the result of wavelet cross-spectral analysis between solar irradiance and Asian-Pacific thermal contrast indices during 1000-1985. There is a significant 8-30-year period during 1200-1900, a significant 55-100year period during 1200-1550, and a 120-190-year period during 1160-1770. Coherence spectrum analysis was performed for the entire period of 1000-1985. The result shows that there are significant relationships between thermal contrast and solar irradiance at periods of 250 years, 120-160 years, 60-70 years, and 15 years, significant at the $95 \%$ confidence level, suggesting some significant interactions between solar radiation and the ocean-land thermal contrast over the East Asian monsoon region during these periods.

Solar irradiance exhibits abrupt changes on the decadal-centennial scale. Figure 4(a) shows the running t-test value of the 50-year mean solar irradiance index. In the figure, there are six positive maximums (significant at the $95 \%$ confidence level), appearing in 1082 of the MWP and in $1350,1484,1592,1728$ and 1836 of the LIA, which indicate a significant increase in solar irradiance. Seven negative minimums appeared in 1167, 1255 and 1428 of the MWP and in 1529, 1658, 1798 and 1882 of the LIA, indicating a significant decrease in solar irradiance. Figure 4(b) further shows the running $t$-test value of the 200-year mean solar irradiance index. This figure shows that there were four significant centennial-scale abrupt changes in 12941304, 1398-1407, 1601-1610, and 1728-1737. The first abrupt change occurred in the period from the MWP to LIA, with a strong irradiance turning into a weak one. The second abrupt change occurred in the early LIA, with solar irradiance continuing to decrease and then reaching its lowest. The third and fourth abrupt changes occurred in the middle and late LIA, with a significantly strengthening of irradiance.

Compared with the thermal contrast between Asia and
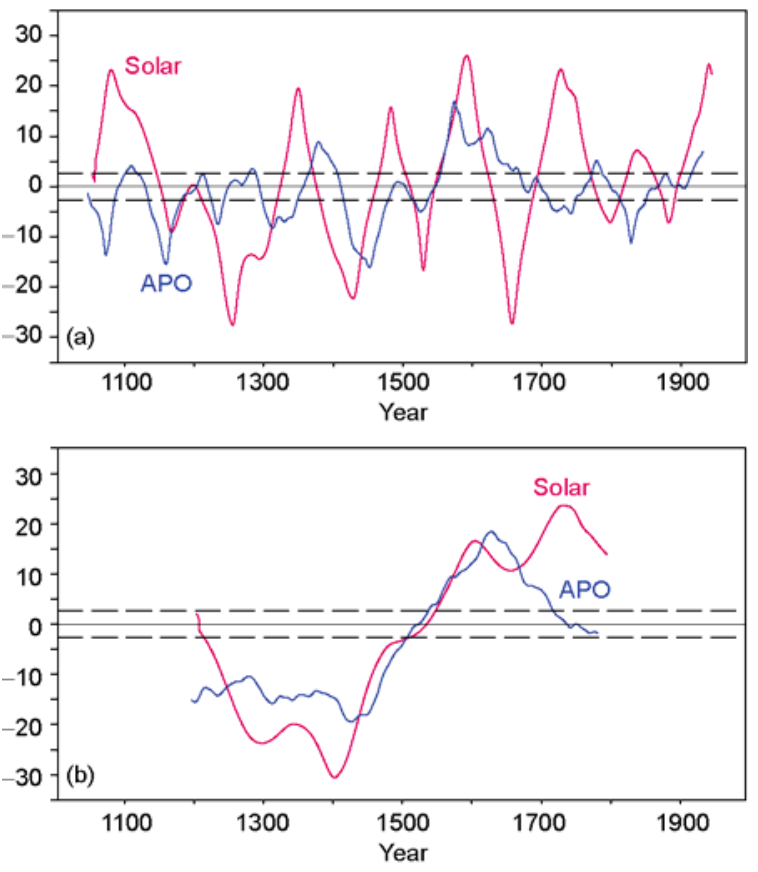

Figure 4 (a) The running $t$-test values (solid line) of the 50-year mean solar irradiance (red line) and APO (blue line) indices, in which the dashed line is the $99 \%$ confidence level, the $x$-axis is year, and the $y$-axis is the $t$-test value; and (b) same as in (a) but for 200-year mean solar irradiance and APO indices. 
the Pacific, on the centennial time scale, the first three abrupt changes in solar irradiance corresponded to those in thermal contrast, and the former usually occurred 12-22 years ahead of the latter. The last abrupt change in irradiance did not correspond to an abrupt change in thermal contrast. On the decadal time scale, however, the abrupt changes in thermal contrast are not synchronous with those in solar irradiance. Five abrupt changes in thermal contrast lagged 20-30 years behind solar irradiance, while two abrupt changes in thermal contrast occurred ahead of solar irradiance. This result implies a weak relationship between them. Therefore, variations in solar radiation are possibly major factors causing climatic changes in the Asian monsoon region on the centennial time scale, while other factors, except solar activity, may also play important roles in climatic changes in the Asian monsoon region on the decadal time scale.

Changes in solar activity cause variations in not only the thermal contrast between Asia and adjacent oceans but also global surface air temperature $[39,40]$. Using the time series of the Northern Hemispheric annual mean surface air temperature over the past millennium reconstructed by Mann et al. [28], we calculated the correlation coefficient between temperature and solar irradiance. The result shows that the correlation coefficient is 0.42 during 1000-1998 (significant at the $99.9 \%$ confidence level). The running $t$-test on the temperature data shows that on the decadal time scale (Figure 5(a)), the temperature showed six significant increases, occurring in 1196, 1366, 1620, 1742, 1842 and 1932. It also
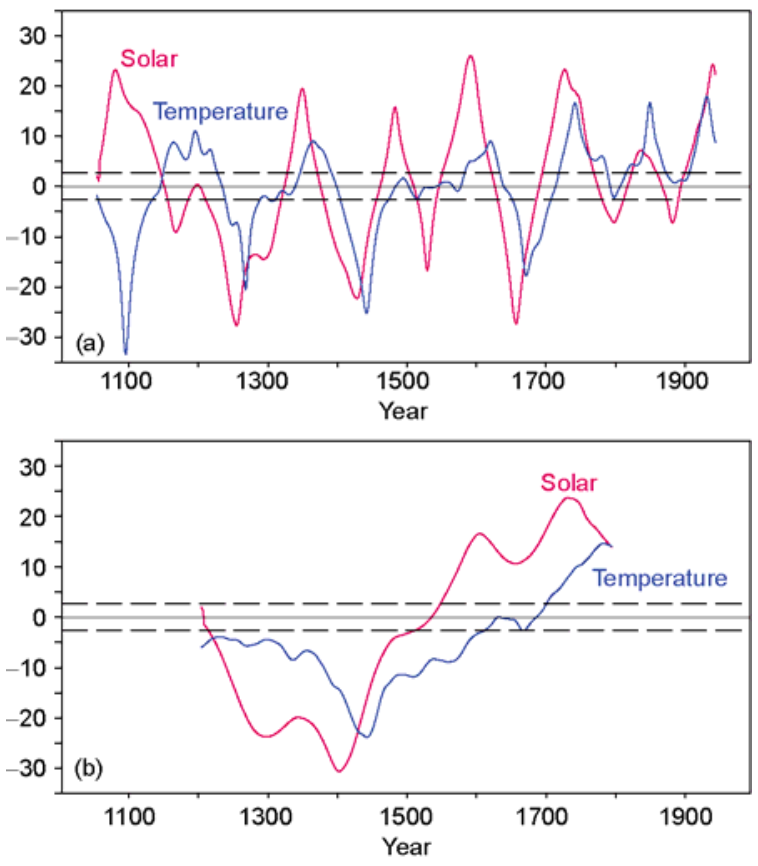

Figure 5 (a) The running $t$-test values of the 50-year mean Northern Hemispheric annual surface air temperature (blue line) and solar irradiance (red line) indices, in which the dashed line is the 99\% confidence level, the $x$-axis is year, and the $y$-axis is the $t$-test value; and (b) same as in (a) but for 200-year mean indices. showed four significant decreases, occurring in 1095, 1268, 1442, and 1672. Since the LIA, there have been seven positive (negative) abrupt changes in temperatures that lagged 14-16 years behind solar activity, which reflects a close link between them on the decadal time scale. On the centennial time scale, the temperature showed one significant abrupt change that occurred in 1437-1446, lagging 40 years behind the abrupt change in irradiance that occurred in 1398-1407. On the centennial time scale (Figure 5(b)), the response of thermal contrast to solar irradiance seems to be faster than that of global mean temperature. Moreover, corresponding to the three abrupt changes in solar irradiance in 1294-1303, 1601-1610 and 1728-1737, there were no significant responses of the Northern Hemispheric mean temperature.

\section{Conclusions}

In the present study, using the reconstructed indices of the summer Asian-Pacific Oscillation (APO) and the solar irradiance over the past millennium and power spectral, wavelet cross-spectral, and running $t$-test analyses, decadal-centennial-scale variations in summer thermal contrast between Asia and the Pacific and its links with solar irradiance were investigated. The results show that thermal contrast was strongest in 1000-1230 and persistently negative in 1420-1625 (weakest over the past 1000 years). Negative values of thermal contrast also dominated in 1740-1940. Over the past millennium, thermal contrast showed periodic oscillations of quasi-90 years, 10-13 years, and 3-7 years. On the centennial time scale, there were three abrupt changes in thermal contrast. The first occurred in 13051315 , corresponding to a decrease in thermal contrast. The second occurred in 1420-1430 and thermal contrast subsequently reached its weakest. The third occurred in 16251635 , corresponding to an increase in thermal contrast.

Long-term change in thermal contrast between Asia and the Pacific is closely associated with solar irradiance. The decrease in solar irradiance in 1100-1400 corresponded to a decrease in thermal contrast, and the lowest irradiance in 1400-1560 corresponded to the minimum value of thermal contrast. Subsequently, irradiance and thermal contrast have been synchronously increasing. The thermal contrast is significantly related to the irradiance at periods of 250 years, 120-160 years, 60-70 years, and 15 years. Three abrupt changes in thermal contrast corresponded to significant changes in solar irradiance and lagged 12-22 years behind irradiance. This link between thermal contrast and solar irradiance may be explained as follows. The summer thermal contrast between Asia and the Pacific is mainly due to the difference in the solar radiative heating between the Asian continent and the Pacific, in which heating of the Tibetan Plateau that strongly responds to solar radiation exerts a stronger influence on the thermal contrast between Asia and the Pacific [29,37,38]. Therefore, when solar 
activity significantly varies, it may cause significant anomalies in Tibetan heating and APO intensity (or thermal contrast), leading to a close relationship between thermal contrast and solar activity. Thus, the abrupt changes in solar irradiance are possibly a reason for the significant climatic changes in the Asian monsoon region on the centennial time scale. On the decadal time scale, however, there was no close relationship between solar irradiance and thermal contrast. This result suggests that besides solar activity, the decadal variations in other forcing factors such as those from the ocean, land, and polar ice and snow outside the Asian-Pacific region also exert influences on the Asian monsoon climate.

Variations in Northern Hemispheric temperature are closely associated with those of solar irradiance. Since the European LIA, the decadal abrupt changes in the Northern Hemispheric annual mean temperature usually lag 14-16 years behind solar irradiance. On the centennial time scale, the three abrupt changes in irradiance did not correspond to the changes in temperature. Only one abrupt change in temperature corresponded to the change in irradiance, lagging 40 years behind irradiance. This result implies that the response of temperature to solar irradiance seems to be slower compared with the thermal contrast between Asia and the Pacific. Identification of the reason for this slow response will require further analysis.

This work was supported by the National Natural Science Foundation of China (40890053 and 40890052) and the National Basic Research Program of China (2007CB815901).

1 Chang C P, Zhang Y, Li T. Interannual and interdecadal variations of the East Asian summer monsoon and tropical Pacific SSTs. Part II: Meridional structure of the monsoon. J Clim, 2000, 13: 4326-4340

2 Nan S, Li J. The relationship between the summer precipitation in the Yangtze River valley and the boreal spring Southern Hemisphere annular mode. Geophys Res Lett, 2003, 30: 1-4

3 Yang F, Lau K M. Trend and variability of China precipitation in spring and summer: Linkage to sea-surface temperatures. Int J Climatol, 2004, 24: 1625-1644

4 Zhang Y, Li T, Wang B. Decadal change of the spring snow depth over the Tibetan Plateau: The associated circulation and influence on the East Asian summer monsoon. J Clim, 2004, 17: 2780-2793

5 Wu B Y, Yang K, Zhang R H. Eurasian snow cover variability and its association with summer rainfall in China. Adv Atmos Sci, 2009, 26: 31-44

6 Zhao P, Zhang X D, Zhou X J, et al. The sea ice extent anomaly in the North Pacific and its impact on the East Asian summer monsoon rainfall. J Clim, 2004, 17: 3434-3447

7 Zhao P, Yang S, Yu R C. Long-term changes in rainfall over Eastern China and large-scale atmospheric circulation associated with recent global warming. J Clim, 2010, 23: 1544-1562

8 Zhu K Z. Preliminary research on climatic variation in China over the recent 5000 years (in Chinese). Sci China, 1973, 3: 168-189

9 Zheng J Y, Zheng S Z. An analysis on cold/warm and dry/wet in Shandong Province during historical times (in Chinese). Acta Geogr Sin, 1993, 48: 348-357

10 Yao T D. Climatic and environmental record in the past about 2000 years from the Guliya ice core (in Chinese). Quat Sci, 1997, 17: $52-61$
11 Wang S W, Ye J L, Gong D Y. Climate in China during ice age (in Chinese). Quat Sci, 1998, 18: 54-64

12 Ge Q S, Zheng J Y, Man Z M, et al. Reconstruction and analysis on the series of winter-half-year temperature changes over the past 2000 years in eastern China (in Chinese). Earth Sci Front, 2002, 9: 169-181

13 Liu J, Chen X, Wang S M, et al. The climate modeling of Little Ice Age (in Chinese). Prog Nat Sci, 2004, 14: 462-468

14 Yang B, Braeuning A. Temperature variations on the Tibetan Plateau during the last millennium (in Chinese). Adv Clim Change Res, 2006, 2: 104-107

15 Zhang D, Liu Y W. A new approach to the reconstruction of temporal rainfall sequences from 172401904 Qing Dynasty weather records for Beijing (in Chinese). Quat Sci, 2002, 22: 199-208

16 Wang S W, Gong D Y. China temperature in several characteristic periods of the Holocene (in Chinese). Prog Nat Sci, 2000, 10: 325332

17 Wang S W, Wen X Y, Luo Y, et al. Reconstruction of temperature series of China for the last 1000 years. Chinese Sci Bull, 2007, 52: 3272-3280

18 Wei J, Tang M C, Feng S, et al. Interdecadal fluctuation of Asian summer monsoon and their relation to astronomical factors (in Chinese). Plateau Meteorol, 1999, 18: 179-184

19 Kodera K. Solar influence on the Indian Ocean monsoon through dynamical processes. Geophys Res Lett, 2004, 31: L24209, doi: 10.1029/2004GL020928

20 Wu J L, Yu Z C, Zeng H A, et al. Possible solar forcing of 400- year wet-dry climate cycles in northwestern China. Clim Change, 2009, 96: 473-482

21 Pan J, Li C Y, Gu W. The possible impact of solar activity on summer rainfall anomaly in Eastern China (in Chinese). Sci Meteorol Sin, 2010, 30: 574-581

22 Zhang P Z, Cheng H, Edwards R L, et al. A test of climate, sun, and culture relationships from an 1810-year Chinese cave record. Science, 2008, 322: 940-942

23 Li C, Yanai M. The onset and interannual variability of the Asian summer monsoon in relation to land-sea interactive thermal contrast. J Clim, 1996, 9: 358-375

24 Zhao P, Zhu Y N, Zhang R H. An Asia-Pacific teleconnection in summer tropospheric temperature and associated Asian climate variability. Clim Dyn, 2007, 29: 293-303

25 Sun X R, Chen L X, He J H. Relationships of the thermal contrast index between land and ocean in East Asia to the intensity of East Asian summer monsoon (in Chinese). In: He J H, Ding Y H, Gao H, et al., eds. Dates of Summer Monsoon Onset in the South China Sea and Monsoon Indices. Beijing: China Meteorological Press, 2001. 96-108

26 Zhou X J, Zhao P, Liu G. Asian-Pacific Oscillation index and variation of East Asian summer monsoon over the past millennium. Chinese Sci Bull, 2009, 54: 3768-3771

27 Bard E, Raisbeck G, Yiou F, Jouzel J. Solar irradiance during the last 1200 years based on cosmogenic nuclides. Tellus B, 2000, 52: 985-992

28 Mann M E, Zhang Z, Hughes M K, et al. Proxy-based reconstructions of hemispheric and global surface temperature variations over the past two millennia. Proc Natl Acad Sci USA, 2008, 105, doi:10.1073/ pnas. 0805721105

29 Zhao P, Chen J M, Xiao D, et al. Summer Asian-Pacific oscillation and its relationship with atmospheric circulation and monsoon rainfall. Acta Meteorol Sin, 2008, 22: 455-471

30 Liu G, Zhao P, Chen J M. A 150-year reconstructed summer AsianPacific Oscillation index and its association with precipitation over eastern China. Theor Appl Climatol, 2011, 103: 239-248

31 Zhou B T, Zhao P. Modeling variations of summer upper-tropospheric temperature and associated climate over the Asian-Pacific region during the mid-Holocene. J Geophy Res, 2010, 115: D20109, doi:10.1029/2010JD014029

32 Zhao P, Yang S, Wang H J, et al. Interdecadal relationships between the Asian-Pacific Oscillation and summer climate anomalies over 
Asian, North Pacific and North America during recent 100 years. J Clim, 2011, doi: 10.1175/JCLI-D-11-00054

33 Chen F, Yuan Y J, Wei W S, et al. Correlations between the summer Asian-Pacific Oscillation index and the tree-ring width of pinus massiniana from Sha county, Fujian Province (in Chinese). Quat Sci, 2011, 31: 96-108

34 Ogurtsov M G, Nagovitsyn Y A, Kocharov G E, et al. Long-period cycles of the sun's activity recorded in direct solar data and proxies. Solar Phys, 2002, 211: 371-394

35 Yin Z Q, Ma L H, Han Y B, et al. Long-term variations of solar activity. Chinese Sci Bull, 2007, 52: 2737-2741

36 Reimer P J, Baillie M G L, Bard E, et al. IntCal04 terrestrial radiocarbon age calibration, 0-26 cal kyr BP. Radiocarbon, 2004, 46:
1029-1058

37 Li D. Relationship between variations of surface heating intensity over the Tibetan Plateau and the solar activity (in Chinese). Plateau Meteorol, 2006, 25: 975-982

38 Zhou X J, Zhao P, Chen J M, et al. Impacts of thermodynamic processes over the Tibetan Plateau on the Northern Hemispheric climate. Sci China Ser D-Earth Sci, 2009, 52: 1679-1693

39 Scafetta N, West B J. Phenomenological solar contribution to the 1900-2000 global surface warming. Geophys Res Lett, 2006, 33: L05708

40 Scafetta N, West B J. Phenomenological reconstructions of the solar signature in the Northern Hemisphere surface temperature records since 1600. J Geophys Res, 2007, 112: D24S03

Open Access This article is distributed under the terms of the Creative Commons Attribution License which permits any use, distribution, and reproduction in any medium, provided the original author(s) and source are credited. 